\title{
Health-related quality of life in children with chronic kidney disease in Assiut, Egypt
}

\author{
${ }^{1}$ Manal M. M. Darwish, ${ }^{1}$ Shimaa H. Hassan, ${ }^{2}$ Samaher F. Taha, ${ }^{1}$ Hosnia S. Abd El- \\ Megeed, ${ }^{1}$ Taghreed A. M. Ismail
}

${ }^{1}$ Public Health and Community Medicine Department, ${ }^{2}$ Assiut University Children Hospital Faculty of Medicine, Assiut University, Assiut, Egypt.

Submitted:22-07-2020 Revised:23-08-2020 Accepted:24-08-2020

\begin{abstract}
Background: Chronic kidney disease (CKD) is known to be one of the major health issues in children under the age of 18 years. CKD affects every organ in the body therefore, has a major consequence on both mortality and quality of life (QoL) of children. Objective: To compare QoL in diseased and healthy children and find out factors associated with QoL score in children with CKD. Method: a cross sectional comparative study was conducted on 250 children with CKD and 250 healthy peers using the Pediatric qualify of life inventory (PedsQL) 4.0. Results: Healthy children achieved statistically significant higher mean PedsQL ${ }^{\mathrm{MM}}$ in all domains of quality of life in all domains of PedsQL ${ }^{\mathrm{TM}}$. Children on conservative treatment achieved statistically significant higher scores in all domains of PedsQL ${ }^{\mathrm{TM}}$ than those on dialysis. There was no statistically significant difference in all domains of PedsQL ${ }^{\mathrm{TM}}$ regarding the severity of CKD. Children receiving hemodialysis reported lower scores in all dimensions of QoL than children on conservative treatment. Conclusion: HRQoL of children with CKD assessed by PedsQL ${ }^{\mathrm{TM}}$ was lower compared to healthy controls and school functioning was the most affected dimension. Study limitations: Children were recruited during routine follow up or after hemodialysis session so, reported scores were not in direct response to an acute event in disease process requiring hospitalization. Implications: Application of psychosocial counseling program for children and their families together with social and educational support groups to enable children with CKD to live and function independently in adulthood.
\end{abstract}

Key words: chronic renal disease, $C K D$, pediatric, quality of life

Corresponding author: Manal Mohamed Mostafa Darwish e-mail: manaldarwish@aun.edu.eg

\section{Introduction:}

Chronic kidney disease (CKD) is known to be a major public health concern worldwide with increasing prevalence and incidence that threatens to reach a true epidemic. Its actual prevalence and incidence may be underestimated by epidemiologic data as it is usually asymptomatic, especially in early stages. ${ }^{1}$ Because of genetic and environmental factors, the magnitude of CKD differs from one geographical region to another. ${ }^{2}$
Previous studies reported a prevalence of CKD between 15-74.7 per million children. ${ }^{3}$ Other reports showed a high prevalence of CKD in other countries. The prevalence range from $6 \%$ in Europe and North American countries to $18.7 \%$ in Japan. ${ }^{4}$

Recently, the World Health Organization (WHO) has added kidney and urologic disease to the globally tracked mortality information, and this should be a reliable source of such information over time. ${ }^{5}$ 
In a developing country like Egypt, with insufficient resources and low-quality primary health care, end-stage renal disease (ESRD) is possibly the "tip of the iceberg," where patients are diagnosed with the renal disease after they have reached renal failure. The exact incidence and prevalence of CKD in children in Egypt is unknown due to absence of a national registry. ${ }^{2}$

Health-related quality of life (HRQoL) has been described as the subjective perception of an individual's illness, and the effect that illness and its treatment have on the individual's functioning in different domains. ${ }^{6}$

As CKD affects every organ in the body, it has a major impact on both mortality and quality of life (QoL) of children. ${ }^{7}$ Children with CKD are at greater risk for delays in neurocognitive growth and reduced quality of life. ${ }^{8}$

Recently, HRQoL was increasingly recognized as a predictor for treatment success in children with chronic diseases and is recommended to include HRQoL measurement in clinical trials. ${ }^{9}$

The present study aimed to compare QoL in both healthy and diseased children and to find out factors associated with QoL score in children with CKD.

Study hypotheses:Children with CKD have poorer HRQoL than healthy children. HRQoL in children with CKD is affected by several factors

\section{Method}

A cross sectional comparative study was conducted in two sites: health insurance clinic and Assiut University Children Hospital (nephrology outpatient clinic, nephrology department and dialysis unit) in Assiut city- Upper Egypt.

Study participants: 2 groups: 1Diseased children: all eligible school aged children with CKD attended Children University Hospital and the health insurance clinic in Assiut could participate in the study.
Any child (8- $\leq 18$ years) diagnosed as having CKD and receiving any type of renal replacement therapy, conservative treatment, dialysis or kidney transplantation.

Children with acute kidney disease and Children with chronic disease other than CKD were excluded from the study.

2- Healthy children: Apparently healthy children ( $8-\leq 18$ years) recruited from the same or a similar locality of diseased children. Age and sex matched to the patients with no history of any chronic diseases including CKD.

Sample size was calculated using the $G^{*}$ Power version 3.1.9.4. The minimum size of each group (stage of GFR) was estimated based on a statistical significance level of 0.05 and a power of 0.80 and mean difference in QoL between cases and controls (74.78 \pm 14.26 vs $82.87 \pm 13.16$ respectively) ${ }^{9}$. The calculated sample size was 47 child/ group which was increased by researchers to 50 . Using a design effect of 5 (as there are 5 stages of CKD), thus the total sample was 250 children with CKD and 250 healthy children.

All legible ESRD children registered in the dialysis unit in Children University Hospital were included in the study (Total coverage of all ESRD cases). For children on conservative treatment, health insurance clinic works only on Sunday and Tuesday every week whereas the nephrology outpatient clinic in Children University Hospital works five days per week.

A systematic random sample from eligible attendants was used and yielded two days/week/clinic.

\section{Ethical Consideration}

Approval from the Ethics Review Committee of Assiut Faculty of Medicine to conduct this study.

An official permission was obtained from director of health insurance sector for the Middle Upper Egypt for data 
collection from health insurance clinic in Assiut.

An official permission was obtained from the director of Children University Hospital for data collection from the nephrology outpatient clinic, nephrology unit and dialysis unit in Children University Hospital in Assiut.

Preparation of the sociodemographic questionnaire.

Request of the Arabic version of the Pediatric quality of life inventory (PedsQL) 4.0 generic core scales (GCS) from Mapi Research Trust, ePROVIDETM ${ }^{\mathrm{TM}}$ online distribution ${ }^{\mathbf{1 0}}$.

\section{Data collection tools:}

Four tools were used in the study. Tool I: demographic and clinical data questionnaire. Demographic data such as age, sex, residence and education. Clinical data such as duration of the disease, cause of CKD, treatment modality and family history of CKD. (for patients only).

Tool II: Family Socio-economic Scale, revised version $2010 .{ }^{11}$ It assesses family socioeconomic status and consists of 4 elements, Parent's education level (8 items), Parent's occupation (2 items), Total family monthly income (6 items), Lifestyle of the family (12 items). The income element had been adjusted according to the inflation rate. ${ }^{12}$

Tool III: Assessment of health-related quality of life (HRQoL) using the Arabic version of the PedsQL ${ }^{\mathrm{TM}}$ Pediatric qualify of life inventory (PedsQL) 4.0 Generic Core Scales (GCS). It is a 23item questionnaire which includes: Physical subscale (8 items), Emotional subscale (5 items), Social subscale (5 items), School subscale (5 items).

The answer of the PedsQL ask the children to rate each item using a 5-point rating scale ranging from 'never' to 'almost always' as follow: $0 \rightarrow$ never a problem, $1 \rightarrow$ almost never a problem, 2 $\rightarrow$ sometimes a problem, $3 \rightarrow$ often a problem, $4 \rightarrow$ almost always a problem.
The instructions ask how much of a problem each item has been during the past month. ${ }^{13}$

After that, reverse scoring for each subscale from 0-100 scale was done as follows: $0=100,1=75,2=50,3=25,4=0$, so that higher scores indicate a better HRQoL.

The PedsQL ${ }^{\mathrm{TM}}$ yields 3 summary scores: Psychosocial score $=$ sum of the items over the number of items answered in the emotional, social, and school subscales.

Physical score $=$ physical subscale score .

Total score: sum of all the items over the number of items answered on all the scales. $^{14}$

The PedsQL child self-report for ages 812 , and 13-18 years was used.

The Arabic version of the PedsQL ${ }^{\mathrm{TM}}$ has proved to be understandable and feasible to use. It has demonstrated good reliability for both healthy and children with chronic illnesses. It also showed good construct and validity, making it suitable for research and clinical use in Egypt. Cronbach's $\alpha$ internal consistency values for the total and subscale scores exceeded 0.70 . Test-retest reliability was high (reliability coefficient exceeded $0.9) .^{15}$

Internal consistency and clinical validity have been demonstrated. Internal consistencies for the total scale score were as follows: child self-report total score Cronbach's 0.91 ; physical score: Cronbach's 0.87 ; and psychosocial score: Cronbach's $0.86^{\mathbf{1 6}}$.

A pilot study was carried out on $10 \%$ of the sample to determine the administrative procedures needed, test the feasibility, assess clarity of the questions, the need for any rewording and/or rephrasing and to assess time required for its filling. No modification was required in the questionnaire and the average time required for its filling was about 20-25 minutes depending on the response of the participants. 
Operational definitions: Children with CKD: any child presented with kidney damage ( any structural or functional abnormality involving pathological, laboratory or imaging findings) for $\geq 3$ months and/or a glomerular filtration rate $(\mathrm{GFR})<60 \mathrm{ml} / \mathrm{min} / 1.73 \mathrm{~m}^{2}$ for $\geq 3$ months. ${ }^{17}$

Markers of kidney damage (one or more). ${ }^{18}$ : Albuminuria, urine sediment abnormalities, electrolyte, or other abnormalities due to tubular acidosis, abnormalities detected by histology, structural abnormalities detected by imaging, history of kidney transplantation.

End-stage renal disease (ESRD): is defined as irreversible decrease in kidney function, which is severe enough to be fatal in the absence of dialysis or transplantation. ESRD is included under stage 5 of the National Kidney Foundation Kidney Disease Outcomes Quality Initiative classification of chronic kidney disease, where it refers to individuals with an eGFR $<15 \mathrm{~mL} / \mathrm{min}$ per $1.73 \mathrm{~m}^{2}$ body surface area, or those requiring dialysis irrespective of glomerular filtration rate. ${ }^{19}$ (Table 1)

Severity (Staging) of CKD: children with CKD were classified according to the eGFR using Updated Bedside Schwartz formula as follows: eGFR $(\mathrm{ml} / \mathrm{min}$ per $\left.1.73 \mathrm{~m}^{2}\right)=41.3 \times($ Height $/ \mathrm{Scr})$, where height is in meters and Scr (serum creatinine) is in $\mathrm{mg} / \mathrm{dl}^{\mathbf{2 0}}$.

According to the eGFR, children with CKD were classified as follows ${ }^{\mathbf{2 1}}$ :

\begin{tabular}{ccl}
\hline Stage & $\begin{array}{c}\text { GFR } \\
\left(\mathbf{m l} / \mathbf{m i n} / \mathbf{1 . 7 3 \mathbf { m } ^ { 2 }}\right)\end{array}$ & \multicolumn{1}{c}{ Terms } \\
\hline Stage 1 & $>90$ & $\begin{array}{l}\text { Normal or } \\
\text { high }\end{array}$ \\
\hline Stage 2 & $60-89$ & $\begin{array}{l}\text { Mildly } \\
\text { decreased }\end{array}$ \\
\hline Stage 3a & $45-59$ & $\begin{array}{l}\text { Mildly to } \\
\text { moderately } \\
\text { decreased }\end{array}$ \\
\hline Stage 3b & $30-44$ & $\begin{array}{l}\text { Moderately to } \\
\text { severed } \\
\text { decreased }\end{array}$ \\
\hline Stage 4 & $15-29$ & Severely \\
\hline
\end{tabular}

The Egyptian Journal of Community Medicine

\begin{tabular}{|c|c|}
\hline & decreased \\
\hline Stage 5 & Kidney failure \\
\hline $\begin{array}{l}\text { Height: chil } \\
\text { classified acc } \\
\text { growth charts }\end{array}$ & $\begin{array}{l}\text { n with CKD were } \\
\text { ding to the Egyptian } \\
\text { ure for age. }\end{array}$ \\
\hline $\begin{array}{l}\text { Growth p } \\
\text { interpretation }\end{array}$ & $\begin{array}{l}\text { neters and their } \\
\text { the WHO. }{ }^{23}\end{array}$ \\
\hline Percentile & Height for age \\
\hline$>99$ & May be abnormal \\
\hline$>97$ & Normal \\
\hline$>85$ & Normal \\
\hline 50 & Normal \\
\hline$<15$ & Normal \\
\hline$<3$ & Stunted \\
\hline$<1$ & Severely stunted \\
\hline
\end{tabular}

\section{Ethical consideration}

The aim of the study was explained to caregivers before starting data collection. Voluntary participation of the child whose caregiver agreed to participate in this study was assured. Verbal informed consent was obtained from both caregivers and children before participating in the study (verbal consent was accepted by Ethical Review Board of Faculty of Medicine, Assiut University (IRB no 17200418) due to the high prevalence of low education levels especially in rural areas, prevailing culture of fear of signing any document and the nature of research which is not interventional, only questionnaire-based). Privacy and confidentiality of all data was assured.

\section{Statistical analysis}

Data entry, cleaning, analysis and recoding (if needed) was done using the Statistical Package for Social Science (SPSS) version 20. Descriptive statistics were calculated as the mean and standard deviation (SD) for continuous variables and as frequency and percentages for categorical variables. Chi-squared $(\chi 2)$ and Fisher's exact tests were used as the test of significance for categorical variables. One-way ANOVA test was utilized for the three or more-group comparison of continuous variables and

$\begin{array}{llll}\text { Vol. } 39 & \text { No. } 2 & \text { April } & 2021\end{array}$


Student-t test for the two-groups. Multivariate linear regression analysis was applied to identify the different

Table (1): Characteristics of the studied children with CKD and matched controls by their socio-demographic characteristics.

\begin{tabular}{|c|c|c|c|c|}
\hline Characteristics & $\begin{array}{c}\text { Cases } \\
(\mathrm{N}=\mathbf{2 5 0})\end{array}$ & $\begin{array}{l}\text { Controls } \\
(\mathrm{N}=250)\end{array}$ & $\begin{array}{c}\text { Statistical } \\
\text { test }\end{array}$ & p-value \\
\hline Age & & & t.test & \\
\hline - Mean \pm SD (Range) & $\begin{array}{l}11.9 \pm 3.1 \\
(8-18)\end{array}$ & $\begin{array}{l}12.1 \pm 2.9 \\
(8-18)\end{array}$ & 0.64 & $>0.05$ \\
\hline \multicolumn{3}{|l|}{ Sex } & \multicolumn{2}{|l|}{$\mathbf{X}^{2}$} \\
\hline $\begin{array}{l}\text { - Male } \\
\text { - Female }\end{array}$ & $\begin{array}{l}168(67.2 \%) \\
82(32.8 \%)\end{array}$ & $\begin{array}{l}157(62.8 \%) \\
93(37.2 \%)\end{array}$ & 1.06 & $>0.05$ \\
\hline \multicolumn{5}{|l|}{ Residence } \\
\hline $\begin{array}{l}\text { - Urban } \\
\text { - Rural }\end{array}$ & $\begin{array}{l}38(15.2) \\
212(84.8)\end{array}$ & $\begin{array}{l}42(16.8 \%) \\
208(83.2 \%)\end{array}$ & 0.23 & $>0.05$ \\
\hline \multicolumn{5}{|l|}{ Education stage } \\
\hline $\begin{array}{l}\text { - Primary } \\
\text { - Preparatory } \\
\text { - Secondary } \\
\text { - No schooling }\end{array}$ & $\begin{array}{l}144(57.6) \\
65(26) \\
31(12.4) \\
10(4)\end{array}$ & $\begin{array}{l}141(56.4) \\
62(24.8) \\
47(18.8) \\
0(0)\end{array}$ & 13.4 & $<0.05$ \\
\hline \multicolumn{5}{|l|}{$\begin{array}{l}\text { Mother's working } \\
\text { status }\end{array}$} \\
\hline $\begin{array}{l}\text { - Housewife } \\
\text { - Working mother }\end{array}$ & $\begin{array}{l}236(94.4) \\
14(5.6)\end{array}$ & $\begin{array}{l}164(65.6) \\
86(34.4)\end{array}$ & 64.8 & $<0.05$ \\
\hline \multicolumn{5}{|l|}{ Socioeconomic class } \\
\hline $\begin{array}{l}\text { - Low } \\
\text { - Middle } \\
\text { - High }\end{array}$ & $\begin{array}{l}73(29.2 \%) \\
169(67.6 \%) \\
8(3.2 \%)\end{array}$ & $\begin{array}{l}15(6 \%) \\
166(66.4 \%) \\
69(27.6 \%)\end{array}$ & 86.5 & $<0.05$ \\
\hline \multicolumn{5}{|l|}{$\begin{array}{l}\text { Family history of } \\
\text { CKD }\end{array}$} \\
\hline $\begin{array}{l}- \text { Yes } \\
\text { - No }\end{array}$ & $\begin{array}{l}43(17.2 \%) \\
207(82.8 \%)\end{array}$ & $\begin{array}{l}3(1.2 \%) \\
247(98.8 \%)\end{array}$ & 8.4 & $<0.05$ \\
\hline
\end{tabular}

$95 \%$ confidence limit and statistical significance level was considered when $P$-value $\leq 0.05$ for all statistical tests.

\section{Results}

A total of 500 children were included in the study (250 cases \& 250 controls). The mean age of the children with CKD was $11.9 \pm 3.1$ years and for controls was $12.1 \pm 2.9$. Males represented $67.2 \%$ in cases and $62.8 \%$ in controls. Most of cases and controls were residing in rural areas $(84.8 \%$ \& $83.2 \%$ respectively). There was no statistically significant difference in children's age, sex, and residence ( $p$-value $>0.05$ ) between cases and controls. predictors of QoL. Odds ratio was calculated as a measure of association at 
There was a statistically significant difference between cases and controls as regards educational stage, mother's job, socioeconomic status and family history of CKD (P-value< 0.05). (Table 1)

Table (2): PedsQL ${ }^{\mathrm{TM}}$ Generic Core Scales score in the studied children with $\mathrm{CKD}$ and their matched control.

\begin{tabular}{|c|c|c|c|c|}
\hline \multirow{2}{*}{ PedsQL } & Cases $(\mathrm{N}=250)$ & Controls $(\mathrm{N}=\mathbf{2 5 0})$ & t. test & p-value \\
\hline & \multicolumn{2}{|c|}{ Mean \pm SD } & & \\
\hline - Physical & $61.5 \pm 30.2$ & $83.9 \pm 14.5$ & 10.5 & $<0.05$ \\
\hline - Emotional & $66.6 \pm 32.1$ & $78.9 \pm 18.4$ & 5.3 & $<0.05$ \\
\hline - Social & $73.8 \pm 31.6$ & $89.2 \pm 13.3$ & 7.1 & $<0.05$ \\
\hline - Schooling & $48.9 \pm 24.9$ & $76.4 \pm 18.6$ & 13.8 & $<0.05$ \\
\hline - Psychosocial & $63.3 \pm 22.7$ & $81.5 \pm 12.7$ & 11.1 & $<0.05$ \\
\hline Total score & $62.8 \pm 23.4$ & $82.4 \pm 11.3$ & 11.9 & $<0.05$ \\
\hline
\end{tabular}

Table (3): Clinical characteristics of the studied children with CKD.

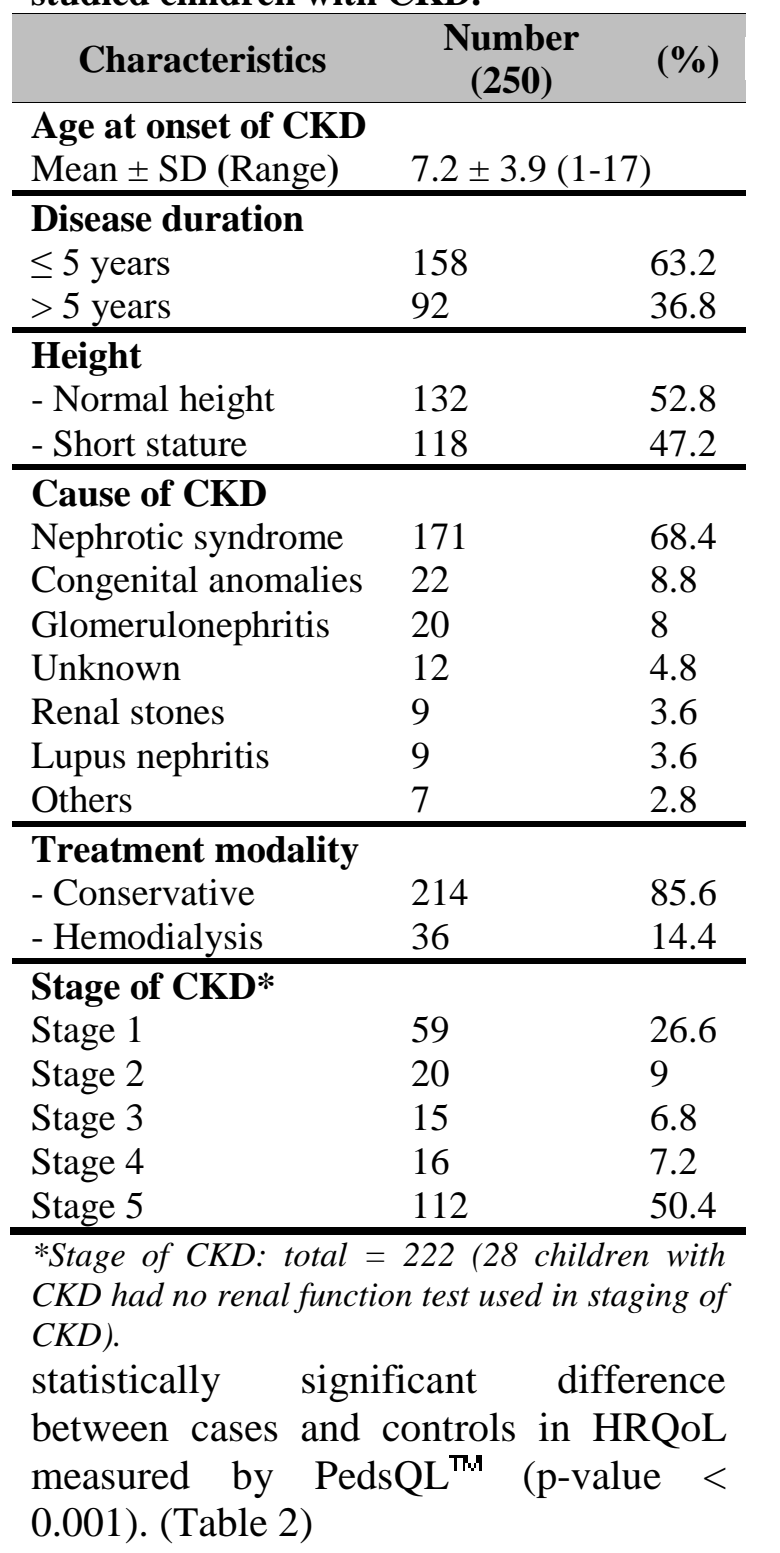

The Egyptian Journal of Community Medicine
As regard HRQoL, healthy children achieved significantly higher mean PedsQL $^{\mathrm{TM}}$ in all domains of QoL than children with CKD. There was
The mean age at onset of CKD was $7.2 \pm$ 3.9 years and the duration of CKD exceeded 5 years in $36 \%$ of cases. Regarding height, $47.2 \%$ of cases had short stature. The most common cause of CKD was nephrotic syndrome $(68.4 \%)$ followed by congenital anomalies $(8.8 \%)$ and glomerulonephritis (8\%).

Most cases (85.6\%) received conservative treatment and $14.4 \%$ were on regular hemodialysis. Regarding CKD severity, about half of the studied children $(50.2 \%)$ were in stage 5 and $26.6 \%$ were in stage 1 CKD. (Table 3 )

Children on conservative treatment achieved statistically significant higher scores in all domains of QoL, except in school function, there was no statistically significant difference. Children with duration of CKD > 5 years achieved higher scores than children with duration $\leq 5$ years, with statistically significant difference only in physical domain and total PedsQL score. There was no statistically significant difference in all domains of PedsQL ${ }^{\mathrm{TM}}$ between different stages of CKD with school function having the lowest score and social domain the highest score in all disease stages.

Children from the middle SES achieved higher scores for QoL than those in the low and middle classes with statistical significance difference in the social, school, psychosocial and total PedsQL ${ }^{\mathrm{TM}}$.

Vol. $39 \quad$ No. 2 April 2021


Children with normal height achieved higher scores in all domains of QoL than children with short stature. There was statistical significance difference in all the domains of PedsQL ${ }^{\mathrm{TM}}$ by height

Table (4): PedsQL ${ }^{T M}$ Generic Core Scales analysis according to independent categorical variables in children with CKD in Children.

\begin{tabular}{|c|c|c|c|c|c|}
\hline & Physical & Emotional & Social & School & Total PedsQL \\
\hline \multicolumn{6}{|c|}{ Treatment modality } \\
\hline Conservative & $67.1 \pm 26.6$ & $69.4 \pm 30.5$ & $77.3 \pm 30.1$ & $50 \pm 23.6$ & $66.4 \pm 21.1$ \\
\hline Dialysis & $28.7 \pm 30.3$ & $49.9 \pm 36.2$ & $53.1 \pm 32.9$ & $42.1 \pm 31.8$ & $41.3 \pm 25$ \\
\hline P.value & $<0.05$ & $<0.05$ & $<0.05$ & $>0.05$ & $<0.05$ \\
\hline \multicolumn{6}{|c|}{ Duration of CKD } \\
\hline$\leq 5$ years & $58.1 \pm 31.5$ & $64 \pm 31.9$ & $72.2 \pm 33.1$ & $48.3 \pm 24.5$ & $60.6 \pm 24.2$ \\
\hline$>5$ years & $67.4 \pm 27.2$ & $70.9 \pm 31.9$ & $76.5 \pm 28.8$ & $50.2 \pm 25.9$ & $66.5 \pm 21.6$ \\
\hline P.value & $<0.05$ & $>0.05$ & $>0.05$ & $>0.05$ & $<0.05$ \\
\hline \multicolumn{6}{|c|}{ Stage of CKD } \\
\hline I & $61.9 \pm 26.6$ & $64.4 \pm 32.6$ & $73.4 \pm 33.2$ & $48.7 \pm 25.5$ & $61.5 \pm 23$ \\
\hline II & $70.3 \pm 26.3$ & $66.5 \pm 28.5$ & $75 \pm 34.3$ & $52.5 \pm 26.5$ & $66.6 \pm 21.7$ \\
\hline III & $63.9 \pm 27.3$ & $70.7 \pm 30.8$ & $72 \pm 38.2$ & $48 \pm 20.4$ & $63.7 \pm 22.1$ \\
\hline IV & $52.9 \pm 26.5$ & $65.3 \pm 37.6$ & $79.4 \pm 31.9$ & $41.5 \pm 16.8$ & $58.9 \pm 19.2$ \\
\hline $\mathrm{V}$ & $58.7 \pm 33.6$ & $64.5 \pm 31.9$ & $70.5 \pm 31.1$ & $49.1 \pm 27.1$ & $61.2 \pm 24.6$ \\
\hline P.value & $>0.05$ & $>0.05$ & $>0.05$ & $>0.05$ & $>0.05$ \\
\hline \multicolumn{6}{|c|}{ Socioeconomic class* } \\
\hline Low & $52.1 \pm 33.5$ & $59.2 \pm 31.5$ & $62.7 \pm 37.3^{\mathrm{a}}$ & $36.8 \pm 28.1^{\mathrm{a}}$ & $53.2 \pm 25.9^{\mathrm{a}}$ \\
\hline Middle & $63.5 \pm 29.5$ & $68.3 \pm 31.5$ & $76.8 \pm 28.6^{\mathbf{b}}$ & $51.5 \pm 24^{b}$ & $65 \pm 21.9^{b}$ \\
\hline High & $63.3 \pm 28.5$ & $67 \pm 34.3$ & $73.1 \pm 34.4^{\mathbf{a , b}}$ & $50.8 \pm 22.1^{\mathbf{b}}$ & $63.5 \pm 24.2^{b}$ \\
\hline P.value & $>0.05$ & $>0.05$ & $<0.05$ & $<0.05$ & $<0.05$ \\
\hline \multicolumn{6}{|l|}{ Height } \\
\hline Normal & $66.9 \pm 26.8$ & $69.3 \pm 30.2$ & $78.8 \pm 27$ & $52.5 \pm 24.3$ & $66.9 \pm 20.2$ \\
\hline Short stature & $55.6 \pm 32.8$ & $63.5 \pm 33.9$ & $68.2 \pm 35.3$ & $44.8 \pm 25.2$ & $58.2 \pm 25.8$ \\
\hline P.value & $<0.05$ & $>0.05$ & $<0.05$ & $<0.05$ & $<0.05$ \\
\hline
\end{tabular}

*ANOVA Post hoc: P.value is significant among subgroups with no similar superscript letter.

and dialysis as a treatment modality, low socioeconomic class, short stature, and shorter CKD duration $(r=-0.38,-0.13$, $0.19,-0.12$ respectively, $\mathrm{P}<0.05, \mathrm{n}=250$ ) (Table 5). Linear regression analysis for predictors of the total PedsQL ${ }^{\mathrm{TM}}$ showed that about $17.2 \%$ of the variations in the total impact score were explained by treatment modality, SES, height and duration of CKD $(\mathrm{R} 2=0.172)$, but only treatment modality (p-value $<0.001, \mathrm{CI}=$ 15.3 - 31) was significant predictors for the total PedsQL ${ }^{\mathrm{TM}}$. (Table 5)

\section{Discussion:}

In this study, the HRQoL assessed by PedsQL $^{T M}$ was statistically significant except with the emotional domain. (Table 4)

Using Spearman Rank correlation, there was statistically significant negative correlation between high total PedsQL ${ }^{\mathrm{T}}$ 
using the Personal Wellbeing IndexSchool Children, the mean score was significantly lower in kidney disease groups than in the healthy group. ${ }^{30}$

Table (5): Correlation and Multiple linear regression of predictors of total PedsQL ${ }^{\mathrm{MM}}$ Generic Core Scales score in the studied children with CKD.

\begin{tabular}{|c|c|c|c|c|c|c|}
\hline \multirow{2}{*}{ Variable } & \multicolumn{2}{|c|}{ Correlation* } & \multicolumn{4}{|c|}{ Regression } \\
\hline & $\mathbf{r}$ & sig & Beta & $\mathbf{t}$ & Sig. & $95 \%$ CI \\
\hline - Treatment modality & -0.38 & $<0.05$ & 0.35 & 5.8 & $<0.05$ & $15.3-31$ \\
\hline - Socioeconomic class & -0.13 & $<0.05$ & 0.11 & 1.9 & $>0.05$ & $0.4-9.1$ \\
\hline - Height & -0.19 & $<0.05$ & 0.09 & 1.3 & $>0.05$ & $1.4-9.3$ \\
\hline - CKD duration & -0.12 & $<0.05$ & 0.08 & 1.3 & $>0.05$ & $1.2-9.9$ \\
\hline Constant & & & & 13.2 & $<0.05$ & $59.8-80.8$ \\
\hline R square & & & 0.172 & & & \\
\hline
\end{tabular}

higher QoL than the general population. The authors suggest that CKD children "live with the illness" and have a lower expectations of their lives since they accept their life as it is. ${ }^{31,32}$

The most marked difference from healthy controls was in school functioning. This may be due to the complex medical treatment and the frequent follow up visits that interfere with school attendance. Family overprotection, fatigue, sleep disturbance and cognitive function impairments associated with deterioration of kidney function also interfere with school attendance. In children undergoing hemodialysis, time of dialysis sessions also interfere with school attendance and study performance in ESRD children. This finding also has been published in other studies. 9 , 24, 27

On the other hand, while the scoring was lower than in healthy children, our children provided the highest scores on the social dimension. This finding may be linked to the use of defense mechanisms or due to narrowing of the intimate community of friends only to the closest community. This finding is consistent with the result of Medyńska et al. $^{33}$ In addition, supportive social reinforcement for adolescents with CKD has been reported to significantly boost QoL and may serve as a protective factor against depression and anxiety. ${ }^{34}$
Unlike our findings, using the Generic Children's Quality of Life Measure, children with $\mathrm{CKD}$ had significantly
In our study, children with CKD reported lower score on physical functioning compared to healthy controls. This adverse effect of CKD in the physical functioning may be attributed to growth impairment and pubertal delay correlated with childhood onset CKD. The physical features such as short stature and bone deformities, which appear during the puberty period, are essential aspects of self-acceptance and self-esteem. ${ }^{33}$

Comparing PedsQL ${ }^{\mathrm{TM}}$ in children with CKD by treatment modality revealed that conservative group achieved statistically significant higher scores in all domains of QoL except in school function as there was no statistical significance difference. Children on dialysis have additional difficulties such as dietary and fluid restriction, use of multiple medications, school absenteeism or drop out of school, social isolation, physical changes, increased behavioral and emotional distress, frequent hospital admission, daily routine changes with dependence on dialysis machine ${ }^{35}$. Dialysis put children on the 'sick role', preventing them from participating normally in daily life as their healthy peers. It is not surprising, considering the restrictions put on them, that children and adolescents with the most aggressive treatment perceived their QoL in the less optimistic side. $^{36}$ 
As the evaluation of school function was generally low in conservative and dialysis groups, no statistically significant difference was identified in school function between both groups, as children on dialysis may also had the benefit of private teaching than children on conservative treatment. Our result is consistent with a recent study that was conducted at Abo El-Reesh Hospital, Cairo University, using the PedsQL ${ }^{\mathrm{TM}}$ and revealed impaired performance in physical, social, emotional and school functions among children with CKD and the worst performance was reported in those on dialysis. ${ }^{37}$

Our results were also supported by previous studies in which dialysis group also rated significantly lower than conservative group in all domains of QoL. ${ }^{25,27,38}$ In the dialysis group, Marciano et al. also found lower scores but with no significant difference. ${ }^{28}$ Using the 50-item Child Health Questionnaire-Parent form, adolescents on dialysis also had lower physical and psychosocial scores than those on conservative therapy. ${ }^{39}$

Regarding the duration of CKD, children with duration of CKD > 5 years achieved higher scores than children with duration $\leq 5$ years, with statistical significance difference only in physical domain. The 'response shift' hypothesis may be an explanation for this surprising result. The response shift indicates that the internal expectations of the patients change as they respond to the diagnosis of their medical conditions, resulting in higher HRQoL as coping with illness becomes a norm. $^{40}$

Contrary to our assumption, HRQoL results do not vary by extent of CKD as there was no statistical significance difference in all domains of PedsQL ${ }^{\mathrm{TM}}$ between different stages of CKD. This could be explained by the fact that the instruments lack sensitivity to differentiate between stages of CKD. ${ }^{36}$ In addition, this lack of association may be explained by the fact that eGFR as a chemical parameter per se cannot consider co-morbidities, social factors or context, psychological makeup and other contributors to HRQoL. ${ }^{41}$ Therefore, longitudinal analysis of HRQoL with decrease in eGFR will be very helpful in detecting the relationship between CKD severity and HRQoL. This finding is consistent with previous studies. ${ }^{36,42,43}$ 27,9

Further analysis revealed that there was statistical significance difference in the social, school, psychosocial and total PedsQL ${ }^{\mathrm{TM}}$ by SES. Children from the middle SES reported higher scores in all domains than those in the higher and lower SES. Low SES affects all aspects of QoL while high SES raises life expectations which cannot be met when CKD is present, resulting in lower QoL scores.

In those with low SES, the effect of CKD increases stress, anxiety and emotional pressure. Several studies link low SES to reduced adherence to treatment and find SES to have a significant effect on children's access to kidney disease prevention and treatment. ${ }^{44}$

Previous study shows that children with low SES (as measured by family income) may experience lower QoL in general. ${ }^{45}$ The Kids with CKD study revealed that children from lower SES are about 1.5 times more likely to experience fair or poor HRQoL compared to those of higher SES. ${ }^{46}$ In comparison, the majority of children in Shtiza et al. study was from low SES, but this was not linked with lower HRQoL scores. ${ }^{18}$

Our study also highlighted the effect of short stature in HRQoL of children with CKD. Statistical significance difference was reported in all the domains of QoL except with the emotional domain as children with short stature achieved lower scores in all domains of QoL. Growth failure in children with CKD 
results from several causes, primarily abnormalities in mineral and bone metabolism. Short stature is considered a major contributor to poor QoL among adolescents with CKD and more than one-third of them were below the 3rd percentile for height and about 45-60\% of adults with childhood-onset CKD have short stature. ${ }^{47}$

Short stature usually has negative physical and psychological impact on the child, affecting the child's self-perceived health and distinguishing him from his peers. Our findings were similar to those published in previous studies. ${ }^{41,45,48,9}$

\section{Conclusion}

HRQoL of children with CKD assessed by PedsQL ${ }^{\mathrm{M} M}$ was lowered compared to healthy controls and school functioning was the most affected dimension. Children receiving hemodialysis reported lower scores in all dimensions of QoL than children receiving conservative treatment. HRQoL was significantly associated with treatment modality, short stature and socioeconomic status, but on multivariate analysis, only treatment modality was significant predictor of HRQoL of the children with CKD.

Strengths and limitations: This study is one of the first studies using PedsQL ${ }^{\mathrm{TM}}$ measures to evaluate the QoL of children with CKD from all aspects. However, Children with CKD were recruited in the study during a routine follow up visit or after hemodialysis session and so the reported scores are not in direct response to a disease exacerbation requiring hospitalization. Also, none of the enrolled children was receiving renal transplantation or peritoneal dialysis, making no chance to compare between these different treatment modalities.

\section{Recommendations}

HRQoL assessment tools should be introduced in the routine clinical care of children with CKD. Further studies on national or multicentric level should be conducted to develop a special program for QoL improvement in children with CKD. Further researches are required to assess the short-term impact of acute events in disease process on children.

\section{Implications:}

Training and encouraging health care provider to offer more psychosocial counselling for children with CKD and their families.

Establishing psychosocial and educational support groups together with group therapy for children with CKD to improve wellbeing, psychosocial adaptation to CKD and share experiences.

Paying more attention to development of social and independent functioning of children with CKD to prepare them for active participation in society in adult life.

Acknowledgements: The authors express their gratitude to children with CKD and their caregivers who participated in the study.

Conflict of interest: The authors have no conflict of interest to declare.

\section{References:}

1. Becherucci F, Roperto R, Materassi M, Romagnani P. Chronic kidney disease in children. Clin Kidney J. 2016;9(4):583-91.

2. Safouh H, Fadel F, Essam R, Salah A, Bekhet A. Causes of chronic kidney disease in Egyptian children. Saudi J Kidney Dis Transpl, 26(4): 806-9.

3. Warady B, Chadha V. Chronic kidney disease in children: the global perspective. Pediatr Nephrol. 2007;22(12):1999-2009.

4. Yousefichaijan P, Rahmati S, Mohammadbeigi A, Rajbaran M. Clinical signs, causes, and risk factors of pediatric chronic kidney diseases: a hospital-based 
case-control study. Int $\mathrm{J}$ Pediat. 2016;4(6):1966-73.

5. Ingelfinger JR, Kalantar-Zadeh $\mathrm{K}$, Schaefer F. World Kidney Day 2016: Averting the legacy of kidney disease-focus on childhood. Pediatr Nephrol. 2016;31(3):343-8.

6. Weissberg-Benchell J, Zielinski T, Rodgers S, Greenley R, Askenazi D, Goldstein S, Fredericks E, Mcdiarmid S, Williams L, Limbers C. Pediatric Healthrelated quality of life: feasibility, reliability and validity of the PedsQL ${ }^{\mathrm{TM}}$ transplant module. Am J Transplant. 2010;10(7):167785.

7. Baum M. Overview of chronic kidney disease in children. Curr Opin Pediatr. 2010;22(2):158-60.

8. Wong C, Moxey-Mims M, Jerry-Fluker J, Warady B, Furth S. CKiD (CKD in children) prospective cohort study: a review of current findings. $\mathrm{Am} \mathrm{J}$ Kidney Dis. 2012;60(6):1002-11.

9. Gerson A, Wentz A, Abraham A, Mendley S, Hooper S, Butler R, Gipson D, Lande M, Shinnar S, Moxey-Mims M. Health-related quality of life of children with mild to moderate chronic kidney disease. Pediatrics. 2010;125(2):e349-e57.

10.Trust MR. Mapi Research Trust, ePROVIDETM $^{\mathrm{TM}}$ online distribution. 2016 [Available from: https://eprovide.mapitrust.org/.[Accessed 16 December 2016].

11.Abdel-Tawab M. Family socio-economic status scale, revised edition. MD thesis in educational basics, Faculty of Education, Assiut University. 2010;MD:32-55.

12.CBE. Central bank of Egypt. Inflalation rate 2017 [Available from: https://www.cbe.org.eg/ar/MonetaryPolicy/P ages/Inflation.aspx. [Accessed 15 April 2017].

13. Varni JW. PedsQL ${ }^{\mathrm{TM}}$ measurement model for the pediatric quality of life inventory TM. 1998 [Available from: http://www.pedsql.org/about_pedsql.html. [Accessed 6 Augest 2016].

14.James W. Varni PD, Trust MR. Scaling and scoring of the pediatric quality of life inventory ${ }^{\mathrm{TM}}$ PedsQL. Lyon, France: Mapi Research Trust. 2015;130:1-140.

15.El-Beh K, Hossam H, Hassaan S, Noomani M. Measuring health-related quality of life in children with chronic medical conditions: reliability and validity of the Arabic version of PedsQL 4.0 generic core scales. Middle East Current Psychiatry. 2018;25(1):16-22.

16.Hullmann S, Ryan J, Ramsey R, Chaney $\mathrm{J}$, Mullins L. Measures of general pediatric quality of life: child health questionnaire (CHQ), DISABKIDS, chronic generic measure (DCGM), KINDL-R, pediatric quality of life inventory (PedsQL) 4.0 generic core scales, and quality of my life questionnaire (QoML). Arthritis Care Res. 2011;63(S11):S420-.S30.

17.Harambat J, Van Stralen K, Kim J and Tizard J. Epidemiology of chronic kidney disease in children. Pediatr Nephrol. 2012;27(3): 363-73.

18.Inker L, Astor B, Fox C, Isakova T, Lash J, Peralta C, Kurella Tamura M and Feldman H. KDOQI US Commentary on the 2012 KDIGO Clinical Practice Guideline for the Evaluation and Management of CKD. Am J Kidney Dis. 2014; 63(5): 713-35

19. Abbasi M, Chertow G and Hall Y. Endstage Renal Disease. Am Fam Physician. 2010; 82(12): 1512-4

20.Schwartz G, Munoz A, Schneider M, Mak R ,Kaskel F, Warady B and Furth S. New equations to estimate GFR in children with CKD. J Am Soc Nephro. 2009; 20(3): 629-37

21.Levin A, Stevens P, Bilous R, Coresh J, De Francisco A, De Jong P, Griffith K, Hemmelgarn B, Iseki K and Lamb E. Kidney Disease: Improving Global Outcomes (KDIGO) CKD Work Group. KDIGO 2012 clinical practice guideline for the evaluation and management of chronic kidney disease. Kidney Int Suppl. 2013;3(1):1-150

22.Charts EG. Cairo University ,Diabetic Endocrine and Metabolic Pediatric Unit and the National Research Center-Cairo, in collaboration with Wright State University. School of Medicine. Department of Community Health Lifespan Health Research Center. 2002 From a total sample size of 33189.

23.Khadilkar V and Khadilkar A. Growth charts: A diagnostic tool. Indian J Endocrinol Metab. 2011; 15 (Suppl) 3: S166-S71

24.Splinter A, Tjaden L, Haverman L, Adams B, Collard L, Cransberg K, Van 
Dyck M, Van Hoeck K, Hoppe B \& KosterKamphuis L. Children on dialysis as well as renal transplanted children report severely impaired health-related quality of life. Qual Life Res. 2018;27(6):1445-54.

25.Shtiza D, Shkurti E. Performance disorders and quality of life in Albanian children and adolescents with CKD. Eur Sci J. 2014;10(7):43-8.

26.Damri T, Louthrenoo O, Chartapisak W, Opastirakul S. Psychosocial problems and quality of life in children with chronic kidney disease. Chiang Mai Med J. 2014;53(3):127-34.

27.Kiliś-Pstrusińska K, Medyńska A, Chmielewska I, Grenda R, Kluska-Jóźwiak A, Leszczyńska B, Niedomagała J, OlszakSzot I, Miklaszewska M, Szczepańska M. Perception of health-related quality of life in children with chronic kidney disease by the patients and their caregivers: multicentre national study results. Qual Life Res. 2013;22(10):2889-97.

28. Marciano R, Soares C, Diniz JS, Lima E, Silva J, Canhestro M, Gazzinelli A, Melo C, Dias C, Silva A. Behavioral disorders and low quality of life in children and adolescents with chronic kidney disease. Pediatr Nephrol. 2011;26(2):281-90.

29. McKenna A, Keating L, Vigneux A, Stevens S, Williams A, Geary DF. Quality of life in children with chronic kidney diseasepatient and caregiver assessments. Nephrol Dial Transplant. 2006;21(7):1899-905.

30.Amr M, El-Gilany A, Bakr A, El Sheshtawy E. Assessment of cognition, behaviour and quality of life of children with chronic renal failure. Paediatrics ME. 2007;12(3):60-6.

31.Heath J, Mackinlay D, Watson A, Hames A, Wirz L, Scott S, Klewchuk E, Milford D, Mchugh K. Self-reported quality of life in children and young people with chronic kidney disease. Pediatr Nephrol. 2011;26(5):767-73.

32. Maxwell H, MacKinlay D, Watson A. Quality of life or health status in children with chronic kidney disease. Pediatr Nephrol. 2010;25(6):1191-2.

33.Medyńska A, Zwolińska D, Grenda R, Miklaszewska M, Szczepańska M, Urzykowska A, Zachwieja K, KiliśPstrusińska K. Psychosocial aspects of children and families treated with hemodialysis. Hemodial Int. 2017;21(4):55765.

34. Oris L, Seiffge-Krenke I, Moons P, Goubert L, Rassart J, Goossens E, Luyckx K. Parental and peer support in adolescents with a chronic condition: a typological approach and developmental implications. J Behav Med. 2016;39(1):107-19.

35.Goldstein S, Gerson A, Goldman C, Furth S. Quality of life for children with chronic kidney disease. Semin Nephrol. 2006;26(2):114-7.

36.Heath J, Norman P, Christian M, Watson A. Measurement of quality of life and attitudes towards illness in children and young people with chronic kidney disease. Qual Life Res. 2017;26(9):2409-19.

37.El-Monem A. Impact of chronic kidney disease on anthropometric profile, healthrelated quality of life and cognitive function in children. Bulletin of Faculty of Physical Therapy. 2019;24(1):26-31.

38.Lopes M, Ferraro A, Koch V. Healthrelated quality of life of children and adolescents with CKD stages 4-5 and their caregivers. Pediatr Nephrol. 2014;29(7):1239-47.

39.Fadrowski J, Cole S, Hwang W, Fiorenza J, Weiss R, Gerson A, Furth S. Changes in physical and psychosocial functioning among adolescents with chronic kidney disease. Pediatr Nephrol. 2006;21(3):394-9.

40.Brossart D, Clay D, Willson V. Methodological and statistical considerations for threats to internal validity in pediatric outcome data: response shift in self-report outcomes. J Pediatr Psychol. 2002;27(1):97107.

41.Harmer M, Wootton S, Gilbert R, Anderson C. Association of nutritional status and health-related quality of life in children with chronic kidney disease. Qual Life Res. 2019;28(6):1565-73.

42.Baek H, Kang H, Choi H, Cheong H, Ha I, Han K, Kim S, Cho H, Shin J, Park Y. Health-related quality of life of children with pre-dialysis chronic kidney disease. Pediatr Nephrol. 2017;32(11):2097-105.

43. Moreira J, Bouissou C, Teixeira A, Simões A, Kummer A. Anxiety, depression, resilience and quality of life in children and adolescents with pre-dialysis chronic kidney 
disease. Pediatr Nephrol. 2015;30(12):215362.

44.Minnick M, Boynton S, Ndirangu J, Furth S. Sex, race, and socioeconomic disparities in kidney disease in children. Semin Nephrol. 2010;30(1):26-32.

45.Francis A, Didsbury MS, Van Zwieten A, Chen K, James LJ, Kim S, Howard K, Williams G, Treidel OB, Mctaggart S. Quality of life of children and adolescents with chronic kidney disease: a crosssectional study. Arch Dis Child. 2018;104(2):134-40.

46.Didsbury M, Van Zwieten A, Chen K, James L, Francis A, Kim S, Mctaggart S, Walker A, Mackie F, Kara T. The association between socioeconomic disadvantage and parent-rated health in children and adolescents with chronic kidney disease - the Kids with CKD (KCAD) study. Pediatr Nephrol. 2019;34(7):1237-45.

47.Ku E, Kwok J. Complications of chronic kidney disease in adolescents. In: Haddad M, Winnicki E, Nguyen S, (eds). Adolescents with chronic kidney disease: from diagnosis to end-stage disease. Cham: Springer 2019. p. 1-15.

48.Al-Uzri A, Matheson M, Gipson D, Mendley S, Hooper S, Yadin O, Rozansky D, Moxey-Mims M, Furth S, Warady B, Gerson A. The Impact of Short Stature on Health-Related Quality of Life in Children with Chronic Kidney Disease. J Pediatr. 2013;163(3):736-41.e1. 